\title{
The Seralini affair: degeneration of Science to Re-Science?
}

\author{
John Fagan ${ }^{1 *}$, Terje Traavik ${ }^{2,3}$ and Thomas Bøhn²
}

\begin{abstract}
A paper reporting findings relevant to safety of the genetically modified (GM) maize NK603 and the herbicide Roundup (Séralini et al., Food Chem Toxicol. 50:4221-4231, 2012) was retracted against the wishes of the authors, and subsequently republished in another peer-reviewed journal (Séralini et al. Environ Sci Europe, doi:10.1186/s12302014-0014-5, 2014). These events exemplify a trend in which disputes, between interest groups vying for retraction and republication of papers that report controversial results, overshadow the normal scientific process in which peer-reviewed publication stimulates new research, generating new empirical evidence that drives the evolution of scientific understanding. This paper reviews the current status of research on safety of NK603 maize and Roundup herbicide for human and livestock health, and attempts to glean from recent developments insights relevant to risk assessment policy for GM crops and pesticides, as well as relevant to the scientific process in general. Our analysis of currently published evidence confirms NK603 and Roundup are kidney and liver toxicants at levels below current regulatory thresholds. Consequently, the regulatory status of NK603, glyphosate and Roundup requires reevaluation. Additionally, preliminary evidence indicates Roundup and NK603, individually and in combination, may increase tumor incidence and mortality. Follow-up long-term carcinogenicity studies, using test animal strains and numbers of animals that assure robust conclusions, are required to confirm/refute this preliminary evidence. The inherent tension between the scientific process and commercial interests of product developers necessitates implementation of safeguards that protect the scientific process and prevent degeneration of Science to Re-Science (typified by retraction and republication disputes).
\end{abstract}

Keywords: GMO, Genetically modified organism, NK603, Pesticide, Glyphosate, Roundup, Regulatory safety assessment

\section{Introduction}

In November 2013, the editors of the journal Food and Chemical Toxicology (FCT) retracted [1] a controversial research paper, with implications for public, animal and ecosystem health [2], against the desires of the authors. In June 2014, this paper was republished in the refereed journal Environmental Sciences Europe (ESEU) [3].

Retracted over a year after publication, this paper presented clear evidence regarding the toxicity of NK603 and Roundup herbicide. Earlier, 90-day toxicity studies generated data $[4,5]$ indicating that the genetically modified (GM) maize, event NK603, (tested in three different

\footnotetext{
*Correspondence: jfagan@eos-institute.org

${ }^{1}$ Earth Open Source Institute, P.O. Box 1995, Fairfield, IA 52556, USA Full list of author information is available at the end of the article
}

doses) may be implicated in kidney and liver toxicity in Sprague-Dawley rats. Séralini et al. [2, 3] presented evidence from longer term toxicity studies that confirmed earlier findings. This work also reported that Roundup herbicide formulation (tested in three different doses) causes liver and kidney toxicity at levels well below the regulatory threshold set for glyphosate, alone. This was the first study to investigate effects of a Roundup formulation. All earlier studies investigated glyphosate, the herbicidal ingredient of Roundup, in isolation. The genetically modified maize NK603, Roundup and the two in combination were also reported to increase mortality and tumor incidence. The study was designed as a toxicological study, not as a carcinogenesis study. Therefore, the tumor incidence and mortality results were reported, according to OECD guidelines for chronic toxicity 
studies [6], as secondary observations requiring followup using a study design intended to systematically assess carcinogenesis.

With Séralini et al. [2] once again part of the peerreviewed scientific literature, the present article attempts to glean from the events surrounding this article insights relevant to the risk assessment process for genetically modified crops and their required co-technologies, such as herbicides, and insights relevant to the broader process by which scientific knowledge is generated. The article also summarizes the current state of research related to the safety of the genetically modified maize NK603 and the herbicide Roundup.

\section{Initial publication and public dialog}

Vigorous public discussion of Séralini et al. [2] commenced through multiple communication channels within hours of publication. Reviewing this exchange, it is clear that much of it consisted of robust discussion among scientists and regulators aimed at clarifying various aspects of the research results and understanding the ramifications for regulatory policy related to safety assessment of GM crops and pesticides. However, it soon became apparent that, superimposed on this scientific discussion, there was an industry-driven media and lobbying campaign aimed at both the research and research team. An article in The Guardian [7] described the campaign as "a triumph for the scientific and corporate establishment which has used similar tactics to crush other scientists".

The Science Media Center (SMC) and its spinoffs in Japan, Canada, Australia, and New Zealand, which receive substantial funding from agricultural biotech companies [8], played a central role in this campaign, broadcasting communications aimed at science journalists. These communication efforts succeeded in reducing press coverage of the Seralini publication world-wide, according to the head of SMC [9].

A second element was an email campaign urging scientists to write to FCT demanding that Séralini et al. [2] be retracted (documented in Langridge [10]). The resultant letters represented the majority of letters published in FCT that were critical of the paper. A third element of the campaign was a petition sponsored by AgBioWorld [11], which has long-standing industry links [12].

Two months after publication of Séralini et al. [2], the Séralini research group published a systematic response to criticisms voiced in letters published in FCT [13].

Consecutively to the month-long campaign by the biotechnology industry, FCT created a new position, Associate Editor for Biotechnology, to which they appointed Richard Goodman, a past employee of Monsanto. The major agricultural biotechnology companies continue to fund his research at the University of Nebraska [14].
Goodman has been closely linked to the International Life Sciences Institute (ILSI), an industry-funded organization with a history of lobbying for industry-friendly risk assessment regulations for GM crops and pesticides. World Health Organization (WHO) has barred ILSI from participating in WHO safety standards setting processes [15], following publication of reports by WHO in 2001 and 2003, criticizing ILSI $[16,17]$.

\section{Imposed retraction}

Not long after Goodman's appointment as Associate Editor for Biotechnology, Séralini and colleagues were requested to provide all raw data to FCT for review and were subsequently informed their paper would be retracted. Although the Editor-in-Chief published assurances that Goodman did not have access to the raw data provided to FCT, it is clear that he was involved in the internal review, although this involvement was later terminated at Séralini's request [18].

The essence of the retraction notice [1] is as follows:

"A more in-depth look at the raw data revealed that no definitive conclusions can be reached with this small sample size regarding the role of either NK603 or glyphosate in regards to over-all mortality or tumor incidence".

"Ultimately, the results presented (while not incorrect) are inconclusive, and therefore do not reach the threshold of publication for Food and Chemical Toxicology".

Subsequently, in response to several letters to FCT criticizing the retraction, Hayes published an expanded explanation [18], the core of which is as follows:

"According to the COPE [Committee on Publication Ethics] guidelines, 'Journal editors should consider retracting a publication if... they have clear evidence that the findings are unreliable, either as a result of misconduct (e.g. data fabrication) or honest error (e.g. miscalculation or experimental error).' [19] .... The data are inconclusive, therefore the claim (i.e., conclusion) that Roundup Ready maize NK603 and/ or the Roundup herbicide have a link to cancer is unreliable".

"The review of the data made it clear that there was no misconduct. However, to be very clear, it is the entire paper, with the claim that there is a definitive link between GMO and cancer that is being retracted".

Hayes' justification for retraction contains questionable points: 
First, the central findings of the study, that Roundup and NK603 together and individually caused hepatic and renal damage in the exposed Sprague-Dawley rats, are not inconclusive. These findings, based on biochemical measurements from blood samples, are statistically significant and were generated from numbers of animals recognized by OECD as appropriate for chronic toxicity studies ( $\mathrm{n}=10$ animals per group). In and of themselves, these findings warrant publication. Hayes ignores these central findings and focuses on tumors and mortality only.

Second, Hayes' justification hinges on the misunderstanding that Séralini claimed a "definitive link between GMO and cancer". This is clearly incorrect. The actual conclusions of the paper are as follows:

1. "[...] lower levels of complete agricultural glyphosate herbicide formulations, at concentrations well below officially set safety limits, induce severe hormone-dependent mammary, hepatic and kidney disturbances",

2. "[...] disruption of biosynthetic pathways that may result from overexpression of the EPSPS transgene in the GM NK603 maize can give rise to comparable pathologies [mammary, hepatic and kidney disturbances] that may be linked to abnormal or unbalanced phenolic acids metabolites, or related compounds. Other mutagenic and metabolic effects of the edible GMO cannot be excluded. This will be the subject of further studies",

3. "This study represents the first detailed documentation of long-term deleterious effects arising from the consumption of GM R[oundup]-tolerant maize and of R[oundup]...,

and

4. "[...] significant biochemical disturbances and physiological failures documented in this work confirm the pathological effects of these GMO and R[oundup] treatments in both sexes, with different amplitudes. We propose that agricultural edible GMOs and formulated pesticides must be evaluated very carefully by long term studies to measure their potential toxic effects."

Moreover, the article does not contain the word "cancer". Although the paper reports the occurrence of tumors, it does not equate these with cancer, and it reports them in the context of OECD Guideline 452 for chronic toxicity studies, which requires that, if, during a chronic toxicology study, increased mortality, or lesions, such as tumors, are observed, these must be reported [6].

Third, Hayes's justification is based on an incorrect reading of the COPE guidelines [20], which recommend retraction if "findings are unreliable, either as a result of misconduct (e.g. data fabrication) or honest error (e.g. miscalculation or experimental error)....”

Hayes inappropriately applied this recommendation by equating "inconclusive" with "unreliable". These are not synonymous. Furthermore, as Schubert [19], Meyer and Hilbeck [21] and others have pointed out, if Hayes' reading of this recommendation were applied uniformly, most of the scientific literature would have to be retracted. It is the nature of research results that they are inconclusive. Or, as David Suzuki asserts: "the very nature of science, is that most of our ideas at the cutting edge of knowledge are wrong. That's how science progresses.... "But we forget that" [22].

Regarding this, Portier et al. [23] state, "To our knowledge, there is no precedent for 'inconclusive data' being a reason for retraction for Elsevier or other publishers, or elsewhere in the scientific literature. To single out this one study for retraction is almost certainly due to the controversy following its publication".

Fourth, FCT does not adhere consistently to the "policy" upon which Hayes based his retraction of Séralini et al. [2], as Séralini et al. [24] state:

"FCT's retraction of our paper, while not retracting
studies-Zhang et al. [25] and Hammond et al. [4]-
is an example of unscientific double standards. The
decision to retract our paper appears to be result-
driven, in that findings of safety in Zhang et al. [25]
and Hammond et al. [4] have not been subjected to
critical analysis and have been allowed to stand,
whereas our findings of risk have been viewed with
suspicion and forcibly retracted. As a result, eco-
nomic interests have been given precedence over
public health".

Meyer and Hilbeck [21] have published an in-depth comparative analysis that included both Séralini et al. [2] and Hammond, et al. [4], which comes to the same conclusion.

It may be that the validity of Hayes' decision has also been questioned within Elsevier since, as of January 2015, he has been replaced as senior editor at FCT, and Goodman is no longer listed as part of the FCT editorial board.

Another, more recent publication, Reznick [26] also agrees that, "inconclusiveness, by itself, is not a sufficient reason for retracting an article.... Despite, seeming to be critical of the conclusions of Séralini et al. [2,3], this article also makes clear that retraction due to inconclusiveness is not in accordance with the COPE guidelines [20] for retraction of published papers. Reznick [26] also ask the question, "How was a paper that the editors said did not meet the journal's scientific standards approved for publication in the first place?" The author concludes, "Journals that are reviewing studies with significant 
scientific and social implications should take special care to ensure that peer review is rigorous and fair".

\section{Republication}

Séralini et al. [2] has now been republished in the open access journal Environmental Sciences Europe (ESEU). Unsurprisingly, controversy has already arisen regarding the republished paper. According to a journalist at Nature [27], ESEU "conducted no scientific peer review" of Séralini, et al. [3], and the "role of the three reviewers that ESEU hired was to check that there had been no change in the scientific content of the paper". Henner Hollert, editor-in-chief of $E S E U$, is quoted as saying that this approach was taken because a scientific peer review "had already been conducted by Food and Chemical Toxicology, and had concluded there had been no fraud nor misrepresentation".

Industry advocates have argued that this means that the paper was republished without peer review, and Reznick [26] reiterates this view. However, the perspective of ESEU seems to be that they accepted as valid FCT's original peer review, and used their own peer reviewers to verify that the scientific content of the resubmitted paper was unchanged. Hence, the conclusions of the previously published peer-reviewed paper in FCT still stand.

Séralini et al. [3] have also provided all raw data pertinent to the study as an on-line supplement. In an accompanying commentary, Séralini et al. [28] state that all raw data used in regulatory assessments of GM crops and pesticides should also be made public. This point has also been raised by others [29]. Although biosafety data on GMOs are in the public domain in the EU, pesticide data are not, and in many countries, such as the US, large portions of the documentation submitted for approvals of both GMOs and pesticides are classified as confidential business information and are not accessible to the public.

Séralini et al. [28] also point to another area where reform is needed, explaining that currently, GM crop and pesticide developers are allowed to submit to regulators, as evidence of safety of their products, data generated in their own laboratories or in contract laboratories under their supervision. Séralini et al. [28] suggest that the conflicts of interest inherent in this arrangement can be avoided by having such research conducted by independent laboratories. They suggest companies still pay for the research, at levels comparable to current costs, but public tender to carry out the research independent of the company that developed the product would recruit independent researchers. Others have suggested a similar approach for assessing biomedical technologies [30].

\section{Safety of NK603, glyphosate and roundup- current status of the science}

Careful comparison of Séralini et al. [3] and [2] makes clear that the datasets of the two papers are identical. The authors' interpretation of those data and their conclusions are also unchanged. The main differences are clearer presentation and clarification of certain points that had been the subject of debate regarding the first version of the paper.

The two conclusions presented in the original paper still stand. The first was that long-term dietary exposure to genetically modified NK603 maize is linked with statistically significant differences in blood parameters indicative of kidney deficiency and liver congestion/necrosis.

This was not a new finding. Séralini et al. [2,3] is confirmatory of earlier reports of small but statistically significant changes in liver and kidney function linked to 90-day exposure to NK603. Hammond et al. [4] interpreted these changes as not biologically significant, while de Vendômois et al. [5] interpreted them as potential early signs of liver and kidney toxicity. The dataset of the latter study was generated in Monsanto's own laboratories, submitted to EU regulators as part of the approval process for NK603 in Europe, and provided under court order to de Vendômois et al. by the Swedish Board of Agriculture.

Séralini et al. [2,3] was designed as a follow-up to these two reports. It confirmed that the small but statistically significant changes observed in studies of shorter duration do escalate into more severe, statistically significant organ pathologies when duration of exposure was extended beyond 90 days to 2 years.

The second conclusion was that long-term dietary exposure to formulated Roundup herbicide is linked with high statistical significance to substantial increases in incidence of kidney deficiency and liver congestion/necrosis. It has long been recognized that glyphosate exposure at levels above regulatory limits can cause liver and kidney failure [31]. The new contribution of Séralini et al. [2, 3] is that the concentrations of formulated Roundup found to cause liver and kidney damage were as low as $0.05 \mathrm{ppb}$ (containing $50 \mathrm{ng} / \mathrm{L}$ of glyphosate), well below safety limits for glyphosate in EU drinking water. This limit was set based on studies of glyphosate in isolation, not Roundup formulations. Roundup formulations are more effective than glyphosate alone as herbicides, because the adjuvants included in Roundup, allow glyphosate to penetrate plant tissues more effectively, thereby increasing toxicity to animals. Likewise the adjuvants would increase penetration of animal tissues thereby increasing toxicity to animals. The findings of Séralini et al. [2, 3] are also consistent with the epidemiological evidence recently published by Jayasumana et al. [32, 33], linking Roundup to kidney failure in sugar cane plantation workers. 
As in their earlier paper, Séralini et al. [3] also report increased mortality and tumor incidence in rats fed NK603 and Roundup, either together or separately. These observations are presented as preliminary findings, and the authors suggest multiple lines of research to further test their observations.

A recent report from the International Agency for Research on Cancer (IARC) concluded that glyphosate is "probably carcinogenic to humans" (Group 2A chemical) [34]. IARC concluded that evidence for the carcinogenicity of glyphosate in animal studies was conclusive, and cited independent support from mechanistic evidence (genotoxicity and oxidative stress). However, data in humans were limited; therefore, glyphosate was classified as "probably carcinogenic in humans".

The European Food Safety Authority (EFSA) of the European Commission had sharply criticized Séralini et al. [2] and rejected its utility in a regulatory setting [35]. However, even before the paper was republished, the European Commission announced [36] that they would offer funding for research designed to test the observations of Séralini et al. The French government also announced they would fund studies to follow-up Séralini et al. [2]. Unfortunately, the 3-6-month duration and limited scope of measurements proposed for the new French study make it inadequate to serve as a meaningful follow-up. The forum where design of this protocol was discussed included Monsanto and other agricultural biotechnology companies-as well as CRIIGEN, the research organization of the Séralini group. CRIIGEN withdrew from this forum stating that the protocol proposed was inadequate [37].

The protocols for the EFSA and French studies have undergone a number of changes since first announced. The original French protocol was dropped and a new protocol, GMO90+, was developed that is integrated with the protocol designed by EFSA. However, it retains the limitation of the former protocol in that it is only 3-6 months in duration [38] and therefore fails to replicate the time frame of Séralini et al. [2, 3]. The EFSA study includes two sub-studies termed, GRACE and G-TwYST [38]. GRACE only replicates the 90-day time course of Hammond [4]. G-TwYST replicates many of the features of Séralini et al. [2, 3], but has serious limitations, such as using NK603 maize that has been sprayed only once with Roundup. This dosage was selected because it was considered "best practice" [38]. Although this may have been the best practice 10 years ago, today glyphosate resistance of noxious weeds in both North America and Latin America makes at least two, and often three, applications of Roundup necessary. Currently, both the EFSA and the French studies are in progress [38].

\section{Role of rat strain in toxicological and carcinogenesis studies}

Selection of an appropriate animal model is an essential prerequisite for credible and relevant results from feeding studies. This was a point of criticism of Séralini et al. [2, 3], even though their choice was consistent with OECD guidelines and current best practice. OECD Guideline 452 for Testing of Chemicals (pg 4) recommends, "The chronic toxicity study should be carried out in animals from the same strain and source as those used in preliminary toxicity study(ies) of shorter duration" [6].

Séralini et al. [2, 3] was designed as a follow-on study to Hammond et al. [4]. Since Hammond et al. used Sprague-Dawley (SD) rats, it was correct, according to OECD guidelines [6], for Séralini et al. to also use this strain. Séralini et al. [2, 3] interpret their finding of liver and kidney toxicity as being consistent with Hammond et al. [4], confirming that, the observations reported by Hammond et al. were early signs of liver and kidney toxicity. It should be pointed out that the two studies procured SD rats from different sources. This is an undefined variable since sub-lines of outbred stocks of rats (such as $\mathrm{SD})$, propagated in isolation, can undergo genetic drift, complicating comparisons of results between studies.

Increasing sample size is one solution to limitations resulting from both variations in strains from different suppliers and genetic variation within outbred strains. Kacew and Festing [39] point out this has economic impacts, but argue for an alternative solution: "It is possible to incorporate more than one strain of [inbred] animals into existing experimental designs for carcinogenesis screening without increasing the total number of animals or paying any statistical penalty for doing so". At present, OECD guidelines [6, 40] largely leave animal model selection up to the investigator. More stringent guidelines, based on current best practice, could significantly improve rigor and consistency of toxicology and carcinogenicity assessments.

\section{Policy ramifications for safety assessment of GM crops and pesticides}

The papers published by Séralini et al. [2, 3] bring into focus two key issues relevant to government policy for safety assessment of GM crops. First, they make clear that current industry feeding trials, which at most continue for 90 days, or about 10 percent of the lifespan of the test animals, are not adequate for food and feed products meant for daily use. Long-term, if not life-long, toxicity and carcinogenicity studies are called for. EFSA and other regulatory agencies have been edging away from requiring feeding studies of any kind for GM crops [41]. Hopefully, these results will reverse this trend. 
The second issue is the need to assess pesticides and GM crops together, and in the context in which they are used in agricultural practice. Based largely on in vitro tissue culture studies, Roundup formulations are more toxic than the "active" ingredient glyphosate alone [42, 43]. The in vivo studies reported by Séralini et al. [2, 3] also suggest Roundup may be more toxic than glyphosate alone at levels below officially set safety limits, which were established based on studies of glyphosate alone.

The above issues, as well as issues raised in Séralini et al. [28] point to structural biases in regulatory science processes that limit the ability of these processes to protect public, animal and ecosystem welfare. Rectifying this situation requires substantive changes in safety assessment policies. Changes in the right direction would be, for example (a), requiring risk assessments of real technology package combinations, and of actual formulations used in agriculture, like Roundup, and (b) requiring independence of risk assessment research from corporate influence or control.

With the research of Séralini et al. [2] restored as a formal part of the scientific literature [3], it is now incumbent on the regulatory authorities to grapple with evidence presented therein and modify policy accordingly.

Regulators in many countries judge the acceptability of studies for use in regulatory assessment based on whether or not they were carried out according to GLP (Good Laboratory Practice) standards and according to OECD (Organization for Economic Cooperation and Development) guidelines. Séralini, et al. [3] resolves earlier ambiguity, making clear that their research was carried out according to GLP in a GLP accredited laboratory.

It is important to note that OECD guidelines do not exist for safety assessment of GM crops. Typically, regulators have allowed industry to adapt OECD guidelines for toxicity testing of chemicals, in particular OECD guideline 408 (sub-chronic, 90-day, toxicity protocol) [37], for animal feeding studies assessing GM crop safety. Séralini et al. [2, 3] was designed as a follow-on study to Hammond et al. [4], and therefore is consistent with the same adaptation of OECD guideline 408 used by Hammond et al. [4]. However, Séralini et al. [2, 3] added rigor in three ways. (a) They used three doses of NK603 and Roundup. OECD 408 requires 3 doses, but most industry GM crop studies, including Hammond et al. [4], have used only two. Regulators have accepted studies that follow this model, despite this shortcoming. (b) Séralini et al. [2, 3] systematically report observations on 34 organs and 56 blood parameters analyzed at 11 time points, which is a much broader dataset than that recommended in OECD 408 and reported by Hammond et al. [4]. (c) They extended the time scale of the study from
90 days to 2 years. However, Séralini et al. [2, 3] included $\mathrm{n}=10$ animals in each treatment and control group, while Hammond et al. [4] included $n=20$ animals in each group, but analyzed only 10 for blood parameters. Thus, the two studies generated biochemical data from equal numbers of animals. It should be pointed out, however, that Hammond et al. [4] did not disclose the criteria that they used to select for analyzing 10 animals from among the 20 in each group.

In summary, the protocol used in Séralini et al. [2, 3] is at least as consistent with OECD protocols as was Hammond et al. [4] and other studies regulators have accepted as evidence of the safety of GM crops. In addition, Séralini et al. [2, 3] included additional features making it more rigorous and generating additional useful data. Thus, it is justified that regulators take into account the evidence presented in Séralini et al. [2,3] when considering the safety of NK603 and Roundup.

\section{Scientific knowledge and the process of peer review: Re-Publish or Perish?}

The efforts to suppress the research findings of Séralini et al. [2] are not an isolated incident, but are exemplifying a trend that has emerged in recent years. In some cases, earlier efforts have lead to retraction; in others, pressure to retract has not achieved this result. Several examples are summarized by Waltz [44]. The most recent apparent occurrence took place at the same journal, FCT, which retracted Séralini et al. [2]. Mezzomo et al. [45] was retracted by the editors without explanation, but was quickly republished in another peer-reviewed journal [46].

This trend raises larger scientific questions, two of which were expressed aptly by Portier et al. [23]:

"Will these data, which could well have been
accepted by another journal, now be tainted beyond
possibility for inclusion in usual weight-of-evidence
reviews of the body of peer-reviewed science? Will
the response to new science by interested parties now
be focused on dueling attempts to have the paper
retracted rather than on performing additional
studies to replicate or refute the findings?"

The republication of Séralini et al. [2] as Séralini et al. [3] firmly establishes the data presented therein as peerreviewed science that must be considered by scientists and regulators alike. However, as events in the time subsequent to republication attest, efforts to discredit these results continue.

Likewise, the republication makes it unlikely that Hayes' enforced retraction will set a strong precedent, capable of supplanting the traditional response to a paper reporting new and controversial science-performing 
additional research-with "dueling attempts to have the paper retracted".

Portier et al. [23] raise another question bringing into sharp focus society's loss if such a precedent were to be established: "Does this retraction strengthen the scientific process, or does it confuse scientific discourse with public relations?"

In a letter to the editor of The Economist, Ellen Silbergeld, Editor-in-Chief of Environmental Research, criticizes the imposed retraction, pointing out its negative impact on the peer-review process [47]: "I consider this a lamentable decision. I am troubled because as an editor I rely on the critical review of peers to determine acceptability of a paper submitted to my journal, and as a scientist, I rely upon the same system of peer review to receive fair review of my own work. This action introduces a breach in the system of trust, which, with all its faults is, as Churchill said of democracy, better than any other process we have thought of up to this time".

In contributing to the advancement of human welfare, science has been the goose that has laid many golden eggs of great benefit to the business sector. Yet when research results are not in line with short-term business priorities, there seems to be no hesitation to attempt to interfere with and manipulate the scientific process [23, 44].

It is typical and justified for extraordinary research findings to be viewed with skepticism and subjected to more stringent scrutiny. As Stanley Prusiner, Nobel Prize Laureate, said [48], "While it is quite reasonable for scientists to be skeptical of new ideas that do not fit within the accepted realm of scientific knowledge,....the best science often emerges from situations where results carefully obtained do not fit within the accepted paradigms". But industry's often well-funded and persistent lobbying is quite another matter. It introduces obstacles that can significantly slow or sidetrack the scientific process.

"Scientific discourse" whose priority is anything other than progressively unfolding more complete understanding is not scientific discourse, but, as Portier et al. [23] say, "public relations". Taking this path risks killing the goose, and this threatens the greater public good, as well as industry's own best interests.

\section{Conclusions}

Six notable developments emerge as a result of the republication of Séralini et al. [2] as Séralini et al. [3]:

1. Evidence is now part of the peer-reviewed scientific literature implicating NK603 maize and Roundup pesticide as chronic liver and kidney toxicants with potentially significant public and animal health consequences. Séralini et al. [2,3] is not the first study on this topic, but builds on earlier studies $[4,5]$. Although it is the first to assess the toxicity of formulated Roundup, findings are consistent with the existing literature, documenting toxicity of glyphosate alone, showing that formulations are toxic at levels well below regulatory thresholds for glyphosate.

2. Now, it is time for critics of this evidence to provide substantive new empirical evidence that contributes constructively to scientific dialog regarding NK603, glyphosate and Roundup. Four distinct lines of research need to be followed up at this time. First, the logical next step regarding liver and kidney toxicity will be to conduct detailed cause/effect studies. However, given the commercial implications of the toxicity findings, we can also expect additional replicative studies to be conducted to confirm/refute the findings of Séralini et al. [2, 3]. Second, a formal, long-term carcinogenicity study, with larger numbers of animals, is needed to investigate the increased incidence of tumors and mortality unexpectedly observed by Séralini et al. [2, 3]. Third, if carcinogenicity is confirmed, follow-up cause/effect studies are needed to understand the biological processes involved. Finally, evidence of carcinogenicity should be followed up with comparative studies using a set of carefully selected experimental protocols and animal species/strains.

3. The currently extant evidence of liver and kidney toxicity in rats is sufficient to justify a thorough review of the regulatory status of NK603, glyphosate and Roundup.

4. Risk assessment policy needs to be upgraded to consistently include assessment of chronic toxicity of GM crops and formulated pesticides, and to require that products be assessed, not as isolated "active ingredients", but in formulations and combinations, and under conditions, used in actual practice.

5. The conflicts of interest inherent in allowing product developers to conduct the safety assessment research that serves as the basis for regulatory approval of their own products also need to be reconsidered.

6. The events surrounding the imposed retraction of Séralini et al. [2] point to the need to recognize the tension inherent between commercial interests of product developers and the scientific process, and to put in place at least basic safeguards to protect the latter. If this is not done, there is growing risk that the standard of the future will not be Science, but Re-Science, which focuses, not on new research results that build humanity's knowledge base, but on disputes among interest groups for (i) retraction of papers that report inconvenient results, and (ii) republishingthe new Re-Science: Re-publish or Perish. 


\section{Abbreviations}

COPE: Committee on Publication Ethics; EFSA: European Food Safety Agency; EPA: US Environmental Protection Agency; ESEU: Environmental Sciences Europe; FCT: Food and Chemical Technology; GLP: Good Laboratory Practice; GM: genetically modified; GMO: genetically modified organism; ILSI: International Life Sciences Institute; OECD: Organization for Economic Co-operation and Development; SD: Sprague-Dawley; SMC: Science Media Center; WHO: World Health Organization.

\section{Authors' contributions}

$T T, T B$, and JF made substantial contributions to conception and design of the paper. TT, TB, and JF were involved in drafting the manuscript and revising it critically for important intellectual content. All authors read and approved the final manuscript.

\section{Author details}

${ }^{1}$ Earth Open Source Institute, P.O. Box 1995, Fairfield, IA 52556, USA. ${ }^{2}$ GenØkCentre for Biosafety, P.O. Box 6418, 9294 Troms $\varnothing$, Norway. ${ }^{3}$ Faculty of Health Sciences, UIT The Arctic University of Norway, 9019 Tromsø, Norway.

\section{Acknowledgements}

The authors acknowledge their respective institutions for support during the time when this paper was prepared.

\section{Compliance with ethical guidelines}

\section{Competing interests}

TB and TT declare that they have no actual or potential competing interests. JF has no actual or potential competing interests, but was, until November 2013, Chief Scientific Officer at Global ID Group, which provides commercial GMO testing services. Since that date JF has no financial, professional, or personal affiliation with Global ID Group.

Received: 16 March 2015 Accepted: 23 July 2015

Published online: 29 August 2015

\section{References}

1. Hayes AW (2014a) Retraction notice to "Long term toxicity of a Roundup herbicide and a Roundup-tolerant genetically modified maize". Food Chem Toxicol 63:244. http://www.elsevier.com/about/press-releases/ research-and-journals/elsevier-announces-article-retraction-from-journalfood-and-chemical-toxicology\#sthash.VfY74Y24.dpuf. Accessed July 2014

2. Séralini G-E, Clair E, Mesnage R, Gress S, Defarge N, Malatesta M et al (2012) Withdrawn: long term toxicity of a Roundup herbicide and a Roundup-tolerant genetically modified maize. Food Chem Toxicol 50:4221-4231

3. Séralini G-E, Clair E, Mesnage R, Gress S, Defarge N, Malatesta M et al (2014) Republished study: long-term toxicity of a Roundup herbicide and a Roundup-tolerant genetically modified maize. Environ Sci Eur 26:14. doi:10.1186/s12302-014-0014-5

4. Hammond B, Dudek R, Lemen J, Nemeth M (2004) Results of a 13 week safety assurance study with rats fed grain from glyphosate tolerant corn. Food Chem Toxicol 42:1003-1014

5. de Vendômois JS, Roullier F, Cellier D, Séralini G-E (2009) A comparison of the effects of Three GM corn varieties on mammalian health. Int J Biol Sci. 5(7):706-726

6. OECD (Organization for Economic Cooperation and Development) (2009) Test No. 452: Chronic Toxicity Studies. OECD Guidelines for the Testing of Chemicals, Section 4. OECD Publishing. doi:10.1787/9789264071209-en

7. Vidal J (2012) Study linking GM maize to cancer must be taken seriously by regulators. The Guardian. http://www.theguardian.com/environment/2012/sep/28/study-gm-maize-cancer. Accessed July 2014

8. Macilwain C (2012) Two nations divided by a common purpose. Nature 483: 247. doi:10.1038/483247a. http://www.nature.com/news/twonations-divided-by-a-common-purpose-1.10224. Accessed July 2014

9. Jump P (2012) Research intelligence-SHOCK troops check 'poor'GM study. Times higher Education. http://www.timeshighereducation. co.uk/421361.article. Accessed July 2014
10. Langridge $P$ (2013) Letter to the Editor. Food and Chemical Toxicology 53:441. doi:10.1016/j.fct.2012.08.005. Accessed July 2014]

11. AgBioWorld (2012) Scientists call on French researchers to release GMO test data. PRLog. http://www.prlog.org/11999640-scientists-call-onfrench-researchers-to-release-gmo-test-data.html. Accessed July 2014

12. Monbiot G. Corporate Phantoms (2002) The Guardian. http://www. theguardian.com/education/2002/may/29/research.highereducation. Accessed July 2014

13. Séralini G-E, Mesnage R, Defarge N, Gress S, Hennequin D, Clair E, Malatesta $M$ et al (2013) Answers to critics: why there is a long term toxicity due to NK603 roundup-tolerant genetically modified maize and to a Roundup herbicide. Food Chem Toxicol 53:461-468

14. Univ Nebraska Website (2014). http://farrp.unl.edu/fss/richard-goodman. Accessed, June 2014

15. Heilprin J (2006) WHO to rely less on US research institute. Washington Post. 2006, Jan 27

16. WHO (2001) The Tobacco industry and scientific groups-ILSI: A Case Study. ; http://www.who.int/tobacco/media/en/ILSI.pdf. Accessed July 2014

17. Boseley S (2003) WHO 'infiltrated by food industry'. The Guardian 8 January, 2003. http://www.theguardian.com/uk/2003/jan/09/foodanddrink. [Accessed July 2014]

18. Hayes AW (2014) Editor in Chief of Food and Chemical Toxicology answers questions on retraction. Food Chem Toxicol 65:394-395

19. Schubert D (2014) Science study controversy impacts world health. U-T San Diego. http://www.utsandiego.com/news/2014/jan/08/sciencefood-health/. Accessed July 2014

20. COPE (Committee on Publication Ethics) (2009) Retraction Guidelines. http://www.publicationethics.org/files/retraction\%20guidelines.pdf. Accessed July 2014

21. Meyer H, Hilbeck A (2013) Rat feeding studies with genetically modified maize - a comparative evaluation of applied methods and risk assessment standards. Environ Sci Europe 25:33. http://www.enveurope.com/ content/25/1/33

22. Suzuki D (2006) An erratic journey through science and society. AmeriQuests 3:2. http://www.ejournals.library.vanderbilt.edu/ojs/index.php/ ameriquests/article/view/75/80

23. Portier CJ, Goldman LR, Goldstein BD (2014) Inconclusive findings: now you see them, now you don't! Environ Health Perspect 122(2):A36

24. Séralini G-E, Mesnage R, Defarge N, de Vendômois JS (2014) Conclusiveness of toxicity data and double standards. Food Chem Toxicol 69:357-359. doi:10.1016/j.fct.2014.04.018

25. Reznik DB (2015) Retracting inconclusive research: lessons from the Séralini GM Maize Feeding Study. J Agric Environ Ethics. doi:10.1007/ s10806-015-9546-y

26. Zhang M, Zhuo Q, Tian Y, Piao J, Yang X (2014) Long-term toxicity study on transgenic rice with Cry $1 \mathrm{Ac}$ and sck genes. Food Chem Toxicol 63:76-83

27. Casassus B (2014) Paper claiming GM link with tumours republished. Nature. doi:10.1038/nature.2014.15463. http://www.nature.com/news/ paper-claiming-gm-link-with-tumours-republished-1.15463. Accessed July 2014

28. Séralini G-E, Mesnage R, Defarge N, deVendômois JS (2014C) Conflicts of interests, confidentiality and censorship in health risk assessment: The example of a herbicide and a GMO. Environ Sci Eur 26:13. doi:10.1186/ s12302-014-0013-6; http://www.enveurope.com/content/26/1/13. Accessed July 2014

29. Nielsen KM (2013) Biosafety data as confidential business information. PLoS Biol 11(3):e1001499. doi:10.1371/journal.pbio.1001499

30. Schafer A (2004) Biomedical conflicts of interest: a defence of the sequestration thesis-learning from the cases of Nancy Olivieri and David Healy. J Med Ethics 30:8-24. doi:10.1136/jme.2003.005702

31. EPA (Environmental Protection Agency) (2014) Basic information about glyphosate in drinking water. http://water.epa.gov/drink/contaminants/ basicinformation/glyphosate.cfm. Accessed June 2014

32. Jayasumana C, Gunatilake S, Senanayake P (2014) Glyphosate, hard water, and nephrotoxic metals: are they the culprits behind the epidemic of chronic kidney disease of unknown etiology in Sri Lanka? Int J Environ Res Public Health 11:2125-2147. doi:10.3390/ijerph110202125

33. Jayasumana C, Paranagama P, Agampodi S, Wijewardane C, Gunatilake S, Siribaddana S (2015) Drinking well water and occupational exposure to 
herbicides is associated with chronic kidney disease, in Padavi-Sripura, Sri Lanka. Environ Health 14(1):6. http://www.ehjournal.net/content/14/1/6

34. Fritschi L, McLaughlin J, Sergi CM, Calaf GM, Le Curieux F, Forastiere F, Kromhout H, Egeghy P (2015) Carcinogenicity of tetrachlorvinphos, parathion, malathion, diazinon, and glyphosate. Red The Lancet 114: doi:10.1016/S1470-2045(15)70134-8

35. EFSA (European Food Safety Authority) (2012) Review of the Séralini et al. (2012) publication on a 2-year rodent feeding study with glyphosate formulations and GM maize NK603 as published online on 19 September 2012 in Food and Chemical Toxicology. EFSA J 10(10): 2986. doi:10.2903/j. efsa.2012.2986. (10 pp)

36. EU Directorate for Research and Innovation (2013) Cooperation Work Program-FP7-KBBE-2013-FEEDTRIALS. http://www.ec.europa.eu/research/ participants/portal/desktop/en/opportunities/fp7/calls/fp7-kbbe2013-feedtrials.html. Accessed July 2014

37. CRIIGEN. GMO (2014) Monsanto invited to assess itself with 3 million Euros of public money. http://www.criigen.org/communique/86/display/ OGM-Monsanto-invite-a-s-auto-evaluer-avec-3-millions-d-argent-public. Accessed July 2014

38. Schiemann J, Steinberg P, Salles B (2014) Facilitating a transparent and tailored scientific discussion about the added value of animal feeding trials as well as in vitro and in silico approaches with whole food/ feed for the risk assessment of genetically modified plants. Arch Toxicol 88(12):2067-2069. doi:10.1007/s00204-014-1375-7

39. Kacew S, Festing MFW (1996) Role of rat strain in the differential sensitivity to pharmaceutical agents and naturally occurring substances. J Toxicol Environ Health 47:1-30

40. OECD (Organization for Economic Cooperation and Development) (1998) Test No. 408: repeated dose 90-Day oral toxicity study in rodents. OECD Guidelines for the Testing of Chemicals, Section 4. OECD Publishing. doi:10.1787/9789264070707-en
41. EFSA (European Food Safety Authority) (2008) Safety and nutritional assessment of GM plants and derived food and feed: The role of animal feeding trials. Food Chem Toxicol 46(Suppl 1):S2-S70. doi:10.1016/j. fct.2008.02.008

42. Cuhra M, Traavik T, Bøhn T (2013) Clone- and age-dependent toxicity of a glyphosate commercial formulation and its active ingredient in Daphnia magna. Ecotoxicology 22:251-262. doi:10.1007/s10646-012-1021-1

43. Benachour N, Sipahutar H, Moslerni S, Gasnier C, Travert C, Séralini G-E (2007) Time- and dose-dependent effects of roundup on human embryonic and placental cells. Arch Environ Contam Toxicol 53:126-133

44. Waltz E (2006) Battlefield_-Papers suggesting that biotech crops might harm the environment attract a hail of abuse from other scientists. Nature 461:27-32

45. Mezzomo BP, Miranda-Vilela AL, de Souza Freire I, Barbosa LC, Portilho FA, Lacava ZG, Grisolia CK (2012) WITHDRAWN: Effects of oral administration of Bacillus thuringiensis as spore-crystal strains Cry1Aa, Cry1Ab, Cry1Ac or Cry2Aa on hematologic and genotoxic endpoints of Swiss albino mice. Food Chem Toxicol. doi:10.1016/j.fct.2012.10.032

46. Mezzomo B, Miranda-Vilela A, Freire I, Barbosa L, Portilho F (2013) Hematotoxicity of Bacillus thuringiensis as Spore-crystal Strains Cry1Aa, Cry1Ab, Cry1Ac or Cry2Aa in Swiss Albino Mice. J Hematol Thromb Dis 1:104. doi:10.4172/jhtd10001042013

47. Silbergeld E (2014) Better to publish. The Economist. http://www. economist.com/news/letters/21592586-narendra-modi-california-cubadominican-republic-patents-academic-publishing. Accessed June, 2014

48. Prusiner SB (1997) Biographical. Nobel prize.org. The Official Web Site of the Nobel Prize. http://www.nobelprize.org/nobel_prizes/medicine/laureates/1997/prusiner-bio.html. Accessed July 2014

\section{Submit your manuscript to a SpringerOpen ${ }^{\circ}$ journal and benefit from:}

- Convenient online submission

- Rigorous peer review

- Immediate publication on acceptance

- Open access: articles freely available online

- High visibility within the field

- Retaining the copyright to your article

Submit your next manuscript at $>$ springeropen.com 